\title{
LA REPRESENTACIÓN DE LA MUJER MIGRANTE MUSULMANA EN LA PRENSA ITALIANA*
}

\section{THE REPRESENTATION OF IMMIGRANTS MUSLIM WOMEN IN THE ITALIAN MASS MEDIA}

Francesca GIARDINA $^{\star \star}$ Y Esther MÁrQuez-LePE ${ }^{\star \star \star}$

\begin{abstract}
Resumen: Este trabajo analiza, desde una perspectiva de género, las representaciones que transmite la prensa italiana sobre las mujeres migrantes musulmanas. Una imagen que condiciona la manera en que la sociedad percibe a este grupo de población. Para ello se propone un análisis cualitativo de las noticias de tres periódicos italianos de tirada nacional: La Repubblica, Il Resto del Carlino, Corriere della Sera. Indagamos en el tipo de representaciones discursivas (temáticas e imágenes) que se hace sobre estas mujeres desde 2001 a 2018, así como en los contextos de producción (autoría, encuadre y temporalidad) de las noticias en las que aparecen. El análisis de la información nos muestra como la imagen de las mujeres migrantes musulmanas sigue construyéndose desde una mirada cosificada, patriarcal y etnocéntrica, asociada a estereotipos justificados en las ideas de sospecha, sumisión y opresión.
\end{abstract}

* El trabajo que se presenta forma parte de una tesis doctoral en curso que se está realizando dentro del Programa de Doctorado en Estudios Migratorios de la Universidad de Granada. Queremos agradecer al Ministerio de Instrucción Pública italiano la concesión de una licencia por estudios para el desarrollo de esta tesis doctoral.

La traducción al español de autores y autoras italianas es de las autoras del artículo.

** Instituto de Migraciones, Universidad de Granada (francesca1975@ correo.ugr.es)

*** Departamento de Sociología, Universidad de Sevilla (esthermarquez@ us.es) 
Palabras clave: Islam; mujer; musulmanas; prensa; género.

Abstract: This paper analizes the gender perspective of the Italian press concerning immigrant Muslim women. This image determines how society views this group of people. Therefore, a qualitative analysis of the three main Italian newspapers articles (La Repubblica, Il Resto del Carlino, Corriere della Sera) seems appropriate. The investigation is based on the specific type of discursive representation (subject and images) of these women in articles from 2001 to 2018 and the news production context (authors, placing, time). The analysis of this information shows us how the image of immigrant Muslim women is built by the patriarchal and ethnocentric view of stereotypes justified by the idea of suspicion, submission and oppression.

Key words: Islam; woman; Muslims; press; gender.

\section{INTRODUCCIÓN}

Los medios de comunicación son actualmente uno de los principales instrumentos de producción de realidad social además de transmisores de información. Como señala Cáceres (1987), poseen la virtualidad de que aquello que es difundido - las noticiasusurpe el lugar de la propia realidad a la que hace referencia. Es decir, un periódico, una revista o un noticiario muestran su perspectiva de los hechos a través de la información que publican pero, "al prestar atención a ciertos aspectos a expensas de otros y al sugerir ciertas soluciones o respuestas en lugar de otras, los mensajes de los medios de comunicación influyen en algo más que en los temas, influyen en el modo en que la gente piensa sobre esos temas" (McCombs y Evatt 1995, p. 31).

En el caso de la inmigración, el discurso mayoritario de los medios de comunicación, tanto italianos como europeos, se ha caracterizado por ofrecer una imagen estereotipada, problemática y conflictiva de esta población para el país de residencia (Corte, 2002; Gallotti y Maneri, 1998; Maneri 2009; Solano, 2012; Orrú, 2015; Zatti, 2007). Un tratamiento que ha sido criticado y rebatido desde espacios sociales, académicos e institucionales pero que sigue vigente actualmente, como han señalado Orrú (2015) o Solano (2012) para el contexto italiano. 
Pero incluso desde esta imagen negativa de la migración hay ciertos grupos que resultan aún más desfavorecidos. Es el caso de las mujeres migrantes y, concretamente, las musulmanas. Como señala Creighton (2013), los medios tienen unas matrices bastante rígidas en cuanto a la representación de la migración femenina y éstas no reflejan la complejidad de esta experiencia. Es frecuente que muchos medios de comunicación, especialmente cuando se refieren a mujeres migrantes narren de forma incompleta y sesgada solo una parte de la historia, y además se realice desde un enfoque frecuentemente victimizador y paternalista, lo cual contribuye aún más a su marginalización e invisibilización (Solano, 2012).

Nuestro estudio quiere contribuir a ampliar el campo de conocimiento sobre migración y mujeres así como a visibilizar los análisis que desde la perspectiva de género se realizan sobre medios de comunicación y, en concreto, sobre prensa escrita. Para ello pretendemos analizar dos cuestiones fundamentales sobre la representación de las mujeres migrantes musulmanas en la prensa italiana: en primer lugar, las imágenes y discursos que se realizan sobre estas mujeres, analizando los valores y atributos que proyectan sobre ellas y, en segundo lugar, los contextos de producción de dichos discursos, es decir, desde dónde, por quién y cuándo se producen estas representaciones.

\section{MARCO TEÓRICO}

\subsection{Las mujeres migrantes musulmanas en Italia}

El desarrollo del Islam en Italia tiene sus raíces en los años setenta, cuando en los principales centros universitarios italianos se colocaron las sedes locales de la USMI (Unión de Estudiantes Musulmanes en Italia). La cultura italiana se abrió así a la comunidad musulmana, como señala Pacini (2001), produciendo traducciones en lengua italiana de textos árabes. La mayoría de las asociaciones de matiz islámico se desarrollaron en los años ochenta hasta completar su expansión en los noventa (p. 10,11) Hoy se puede estimar que el número de centros islámicos se ha triplicado, siendo reflejo no solo del aumento de la presencia islámica en el país sino de un proceso de arraigo duradero (Chiodelli, 2015). Y aunque aún 
no existen en Italia formas eficaces de estimar la importancia de esta comunidad, según Chiodelli (2015) la religión musulmana es la segunda en importancia dentro del país.

En el año 2018, la población musulmana en Italia ascendía a 2,6 millones de personas, lo que supone un $4,3 \%$ de su población total (ISTAT, 2018). Es un porcentaje inferior a la media europea (que ronda el 5\%) pero ha experimentado un ligero aumento con respecto al año anterior en cerca de 100.000 personas, lo que ha supuesto una subida de un punto porcentual desde el 2017. El 56\% de la población musulmana que reside en el país tiene ciudadanía extranjera y el $44 \%$ posee la nacionalidad italiana (ISTAT, 2018). Las comunidades extranjeras con mayor peso dentro de la población musulmana son la marroquí $(34,8 \%)$ seguida de la albanesa $(15,3 \%)$, tunecina $(8,3 \%)$, rumana $(11,7 \%)$ y filipina $(10,2 \%)$ (ISTAT, 2018). Los datos sobre esta población no aparecen desagregados por sexo, por lo que no sabemos el número de mujeres musulmanas que residen en el país, pero si hacemos una extrapolación de los datos de población extranjera, podemos inferir que cerca del $55 \%$ son mujeres ${ }^{1}$, lo que supondría que cerca de 1,3 millones de mujeres musulmanas residen en Italia en la actualidad.

A pesar de esta significativa presencia en el contexto italiano no existen muchas investigaciones sobre ellas. Los trabajos que hemos localizado (Caridi, 2000; Marchetti, 2004; Monaci, 2016) las incluyen como parte del colectivo migratorio, supeditándolas a la migración masculina. En los casos en los que se las menciona expresamente es para hablar sobre su especificidad dentro del mercado laboral, habitualmente dentro del trabajo doméstico o el sector servicios. Estas investigaciones no se despegan de los tópicos habituales, vinculándolas a una posición de sumisión y subalternidad continua, como señala Gaudino (2019). Y es que el discurso público que se ha difundido sobre ellas reproduce los tópicos habituales de una mirada paternalista, que ignora las transformaciones que protagonizan en la sociedad italiana o el impacto que tienen dentro de las relaciones de género y familiares (Chiappelli, 2009). Para la opinión pública estas mujeres son consideradas como meras "sustitutas" de recambio a pesar de que su desempeño laboral, por ejemplo, en el

1 Según los datos del Istituto Nazionale di Statística (ISTAT), en el año 2018 había un total aproximado de 5.000 .000 de personas extranjeras residiendo en el país, es decir, un $8,5 \%$ de la población total, de la cual el $55 \%$ son mujeres. 
caso del trabajo doméstico, implica una nueva y más equilibrada distribución de los roles dentro del hogar y del trabajo intra-familiar (Chiappelli, 2009).

La escasez de investigaciones sobre esta población pensamos que viene producida, entre otros motivos, porque no ha sido hasta hace poco cuando la mujer ha sido considerada actor migratorio autónomo y la variable género se ha convertido en un factor de análisis en sí mismo, tomándola en cuenta en las investigaciones sobre trayectorias y proyectos migratorios, como señalan Masanet y Ripoll (2008) para el contexto español.

\subsection{La representación de las mujeres migrantes musulmanas en la prensa}

En la representación que se ha hecho por parte de los medios de comunicación de las mujeres migrantes musulmanas convergen, entre otras, las características de la representación del colectivo migratorio, la población femenina y la musulmana. Es lo que Nash describe como "la doble alteridad de las mujeres inmigrantes" (2007, p. 60). Una identidad mediática en la que se muestra la interacción de factores de género y diferencia cultural y, por ello, genera mayor marginalización, cosificación e invisibilización.

Por un lado, estas mujeres han sido representadas dentro del colectivo migratorio. Una población que se ha presentado como asunto problemático y conflictivo para los países de residencia y acogida, como señalan de forma consensuada las investigaciones sobre esta materia (Alsina, 2006; Bañón, 2002; Buisef, 1994; Corte, 2002; Dragoevich y Bodas, 1994; Gallotti y Maneri, 1998; Orrú, 2015; Peñamarín, 1997; Rizo, 2001; Siruana, 2004; Solano, 2012; Zatti, 2007). Tal como indican Sobrados-León y Sánchez (2008), la práctica periodística sobre este tema se podría resumir en las siguientes características: se ha dado un tratamiento superficial, parcial y reduccionista a esta poblacion, se ha primado el sensacionalismo, han prevalecido los tópicos y estereotipos, se ha vinculado a problemas como: delincuencia, inseguridad ciudadana, mafias, prostitución, etc, ha habido una escasa reflexión y crítica sobre las causas que obligan a migrar a miles de personas, se ha dado prevalencia de las fuentes institucionales, silenciado la voz de los y las migrantes, se ha dado una falta de especialización por parte 
de los periodistas y se ha abusado de una victimización de la mujer (Sobrados-León y Sánchez, 2008).

Por otro lado, estas mujeres también participan del discurso sobre población musulmana, que aparece en los medios de comunicación asociada recurrentemente a dos temáticas: el terrorismo de matriz islámica y la llegada de pateras (Solano, 2012). Asimismo, como señala Solano (2012), es frecuente que el lenguaje utilizado para representarla genere distancia social en la ciudadanía, ya que se abusa del alarmismo y la metáfora. Por ejemplo, a través del uso excesivo de palabras como extracomunitario, subrayando el hecho de que alguien no pertenece a la Unión Europea o con la utilización de otras más despectivas como desesperado, pobre o clandestino. En general, como afirma Corte (2002), la comunidad musulmana es entendida como amenaza global en tanto que con su diversidad y su alteridad enfrentan nuestro mundo y nuestra manera de vivir, y los medios de comunicación para exorcizarla y neutralizarla, de forma simbólica e ideológica, han legitimado una distinción entre inmigrados buenos y malos, los que creen en los valores occidentales y los que no.

Y, en tercer lugar, a ellas también les atraviesa el discurso mediático sobre mujeres. En este sentido, los resultados aportados por el proyecto Global Media Monitoring (GMMP) del año 2015 sobre representación de mujeres y hombres en los medios de comunicación en Italia (prensa, radio y televisión) muestran como ha existido de forma generalizada una importante sub-representación de las mujeres en los medios de comunicación. En sus resultados destacan como sólo el $21 \%$ de las noticias en los periódicos italianos (Corriere della Sera, La Repubblica, La Stampa, Il Messaggero, Il Gazzettino, Il Resto del Carlino) tienen a mujeres como protagonistas frente al $79 \%$ en el que son varones. Otro resultado igual de revelador es cómo los medios infrarrepresentan a las mujeres como agentes y las sobrerrepresentan como víctimas (López 2007). Esto sucede tanto en temas que afectan por igual a los dos sexos como accidentes, crímenes o guerras y en las noticias que afectan particularmente a las mujeres como violencia sexual y violencia doméstica, donde además de recibir muy poca cobertura mediática suele ser la voz del hombre la que prevalece (el 64\% de los sujetos que aparecen en el discurso de las noticias son hombres), (GMMP 2015).

Los resultados de ésta y otras investigaciones (Rovetto, 2010; Salas, 2012; Simelio i Solá, 2006) señalan la escasa representación 
que han tenido las mujeres en la información publicada por los medios de comunicación escritos y audiovisuales, recibiendo un tratamiento que a menudo las ha situado como personajes marginales, víctimas, débiles e incapaces. Su presencia en la prensa no se ha incrementado proporcionalmente a su incorporación en los escenarios públicos, económicos, políticos o culturales, y cuando se ha producido se las ha caracterizado mayoritariamente como víctimas pasivas y pacientes, dentro de situaciones anecdóticas u objeto de ironía (Gaudino, 2019). En todo caso como sujetos que no mudan, que no se desarrollan con el pasar del tiempo (Rovetto, 2010). Las diferencias en la representación simbólica de mujeres y hombres en los medios de comunicación y, de forma extensiva, en la sociedad responde a hábitos de pensamiento que afectan al enfoque y tratamiento de la realidad social en los que persiste una mirada androcéntrica, restrictiva y anquilosada que ha expulsado a las mujeres como protagonistas del debate público (Rovetto, 2010).

Este enfoque marginal, victimizador e invisibilizador se acentúa cuando junto al género interaccionan otras variables como el lugar de procedencia o la clase social. Las mujeres migrantes, las víctimas de la violencia doméstica o las trabajadoras sexuales reciben por parte de los medios de comunicación un tratamiento tan negativo que, como advierte Alcoba (2009), incluso llega al menosprecio. En el caso de las mujeres migrantes, la interacción de los factores género y migración resulta ser un catalizador para una mayor marginalización. Se las entiende como víctimas sin proyecto migratorio (Pérez, 2003) y objetos de voluntades ajenas (Creighton, 2013), por lo que sus voces no han tenido cabida en el discurso público, han sido subalternas. Como subraya Bernárdez (2007, p. 275), "las inmigrantes no dicen, sino que son dichas". Esto ha generado una clara discrepancia entre la feminización de las migraciones y las imágenes y referencias sobre mujeres migrantes en prensa (Creighton, 2013).

Añadido a todo lo anterior, cuando se habla de mujeres migrantes musulmanas en la prensa aparecen los tópicos y estereotipos sobre mujer e islam. Como advierte Bruno (2008), una cuestión transversal que se da en la mayoría de los discursos que se realizan sobre estas mujeres es la de la sumisión femenina. El orientalismo continúa omnipresente con los estereotipos que emergen cada vez que los medios occidentales hablan de mujeres con velo como rehenes que rescatar o sujetos que defender (Dedej, 2004). Benach y Tello (2005) recuerdan cómo el feminismo occidental, incluso 
en su defensa de la mujer, no dejaba de estar impregnado de un discurso colonial en el que se afirmaba la superioridad de la cultura blanca al mismo tiempo que generaba una imagen de las mujeres del tercer mundo como un todo homogéneo, un colectivo subalterno, tradicional y sin capacidad de transformación histórica (Salas, 2012). De estos discursos se desprende un paternalismo que emerge en relación a las mujeres musulmanas y, en general, hacia los musulmanes considerados como un cuerpo extraño que tiene que integrarse en la sociedad. Todo lo que se refiere a la cultura y religión del Islam es visto como extraño y marginal e interpretado como una amenaza para la manera de vivir de la población italiana (Gaudino, 2019).

En el caso de las mujeres musulmanas, el prisma de doble alteridad de género y de minoría, como señala Nash (2007), constituye un mecanismo cultural decisivo que niega protagonismo a las mujeres, las supedita a proyectos colectivos y además las esencializa en términos culturales (Creighton, 2013).

\section{METODOLOGÍA}

El objetivo general de este artículo es analizar las representaciones discursivas que se proyectan sobre las mujeres migrantes musulmanas en tres de los principales periódicos de la prensa italiana. Para ello contemplamos dos objetivos específicos: analizar los valores y atributos que se realizan sobre ellas en los artículos publicados, pero también visibilizar los contextos de producción de dichas noticias, es decir, desde dónde, por quién y cuándo.

Nuestra estrategia de investigación se encuentra marcada por dos aproximaciones que tienen que ver con la concepción que tenemos de nuestros sujetos y objeto de estudio. En primer lugar, nos apoyamos en el Análisis Crítico del Discurso (ACD) cuando dice que los medios de comunicación son constructores de la realidad mediante las prácticas de selección y tratamiento de las noticias, ya que influyen de forma significativa en la percepción de la opinión pública sobre un determinado tema (Fairclough, 2003; Van Dijk, 2000). Esto significa que nuestro análisis va a estar mediado por estructuras y relaciones de poder. En segundo lugar, investigar sobre mujeres extranjeras musulmanas supone hablar de relaciones 
de subalternidad, desigualdad y racismo (Martín, 2016), por lo que es necesario adoptar un enfoque de género que permita analizar la forma en la que se crean y perduran sistemas sociales a partir de un determinado punto de vista sobre el sexo, el género y la orientación sexual (Novoa, 2012).

Asumir este planteamiento ha implicado desarrollar un enfoque cualitativo en el que se subraya la importancia de analizar los discursos en dos niveles: el primero, el de las estructuras y acciones cotidianas caracterizadas en términos del tratamiento discriminatorio del 'otro', que podemos observar a través de las imágenes y representaciones que se transmiten en las noticias. El segundo, el relativo a las representaciones mentales compartidas por amplias capas de la población dominante como creencias erróneas, prejuicios, ideologías patriarcales, racistas o etnocéntricas y que podemos identificar a través de los contextos de producción de las noticias (Fairclough, 2003).

La técnica que hemos utilizado ha sido la revisión de fuentes documentales, que nos ha permitido organizar informaciones obtenidas en periodos de tiempo según áreas temáticas estableciendo criterios de revisión y clasificación (Gómez, 2010; Valencia, 2012; Villaseñor, 2008).

Para obtener una representación significativa y relevante del espectro ideológico de los medios de comunicación italianos hemos seleccionado tres de los seis periódicos de mayor tirada nacional: La Repubblica, Il Resto del Carlino y Corriere della Sera, con diferente orientación política ${ }^{2}$. El periodo temporal en el que hemos acotado la búsqueda de información ha sido el intervalo desde el 2001 al 2018. Empezamos la búsqueda de noticias desde el año 2001 por ser la fecha de la caída de las Torres Gemelas y un momento que ha condicionado la visión que Occidente tiene sobre Oriente.

En Italia durante este periodo ha habido una crisis económica que ha producido efectos importantes y complicados para el conjunto de la sociedad como: un aumento de los niveles de desigualdad social y económica, una mayor desconfianza hacia la política y un fuerte debilitamiento de los lazos sociales. De forma paralela se ha

2 Il resto del Carlino se caracteriza por un perfil liberalista conservador, La Repúbblica por una línea más social democrata y el Corriere della Sera por estar situado en el centro izquierda. 
dado una alternancia de gobiernos de derecha e izquierda y, junto a ellos, cambios en las leyes sobre la inmigración, tal como se puede observar en la tabla 1.

TABLA 1

GOBIERNOS Y LEYES SOBRE INMIGRACIÓN EN ITALIA DE 2001 A 2018

\begin{tabular}{|l|l|l|}
\hline \multicolumn{1}{|c|}{ DERECHA } & \multicolumn{1}{|c|}{ IZQUIERDA } & \multicolumn{1}{c|}{ LEYES } \\
\hline & Giuliano Amato, 2001 & \\
\hline Silvio Berlusconi, 2001-2006 & & $189 / 2002$ Bossi-Fini \\
\hline & Romano Prodi, 2006-2008 & \\
\hline Silvio Berlusconi, 2008-2011 & & 160/2008 Pacchetto Sicurezza \\
\hline & $\begin{array}{l}\text { Mario Monti, 2011-2013 } \\
\text { Enrico Letta, 2013-2014 } \\
\text { Paolo Gentiloni, 2016-2018 } \\
\text { Giuseppe Conte, 2018-2019 }\end{array}$ & $\begin{array}{l}\text { 46/2017 Decreto Minniti } \\
\text { (impulsado por Salvini bajo el } \\
\text { Gobierno de Conte) }\end{array}$ \\
\hline
\end{tabular}

Fuente: elaboración propia.

Durante el intervalo temporal en el que situamos nuestra investigación (2001-2018) se aprobaron en Italia cuatro leyes sobre inmigración con diferente nivel de permisividad y restricción, fundamentalmente en el acceso de la población migrante al territorio nacional. En el año 2002 se publicó la ley 189/2002 (Bossi-Fini) que reducía la posibilidad de residencia de los inmigrados en Italia. En el año 2008, la ley 160/2008 "Pacchetto Sicurezza" que introdujo el delito sobre inmigración irregular. En el año 2017, la ley 46/2017 (Decreto Minniti) que reguló una simplificación de las notificaciones de los documentos para los refugiados y también otras normas que facilitaron la protección internacional de las personas. La más reciente es el Decreto Sicurezza dell'On, impulsado por Matteo Salvini como ley 113/2018 sobre inmigración y seguridad. Este decreto desarrolla una serie de normas para restringir la inmigración en Italia y expulsar a la población migrante en situación irregular. Estos hechos permiten entender mejor el contexto de producción de las noticias así como el significado e implicaciones de las representaciones que se difunden a través de las mismas.

El criterio para la inclusión de cada artículo de prensa en la carpeta de análisis ha sido que en el corpus del texto de la noticia 
se incluyeran los términos de búsqueda. Este proceso ha tenido dos fases: en primer lugar, se hizo una explotación de las bases de datos de los periódicos a partir de dos términos de búsqueda: mujer árabe y mujer musulmana. De este primer barrido se obtuvo aproximadamente el 75\% (690 registros) de la información analizada. Posteriormente se amplió la búsqueda con conceptos que aparecían de forma recurrente en el primer corpus documental como velo, pañuelo, hijab, abaya, burka ${ }^{3}$.De este segundo barrido se ha obtenido el $25 \%$ de la información una vez eliminados los registros repetidos. Los resultados se han analizado de forma conjunta (primer y segundo barrido) aún sabiendo que puede haber un pequeño sesgo en relación a las temáticas (protagonismo del velo, pañuelo, etc..) pero la importancia numérica del segundo bloque no es lo suficientemente relevante como para modular significativamente los resultados generales y, como resultado de esta incorporación, tenemos una mayor variedad de discursos y posicionamientos en relación a la temática analizada. El corpus total de artículos analizados ha estado formado por 925 documentos/noticias, 309 del periódico La Repubblica, 141 del Il Resto del Carlino y 475 del Corriere della Sera.

Para el tratamiento de la información se ha empleado como herramienta de apoyo el programa de análisis cualitativo Atlas. ti (Versión 8), a través del cual hemos hecho la codificación de la información. En primer lugar, se llevó a cabo una codificación selectiva, agrupando las noticias según los siguientes criterios: sección donde se ubica la noticia, género y procedencia étnica del autor/a de la noticia, fecha de la publicación y temática que aborda el artículo. Después se llevó a cabo otra codificación más interpretativa, donde se fueron identificando códigos abiertos en relación a la valoración que se hacía de estas mujeres según la temática.

En la siguiente tabla (tabla 2) se puede observar la correspondencia entre las categorías de análisis y los objetivos de la investigación.

3 En este texto nos referimos a prendas de vestimenta femeninas islámicas de la siguiente forma: velo, que es una toca o especie de mantilla que cubre la cabeza y parte o la totalidad del rostro; pañuelo, que es una prenda de forma cuadrada que cubre la cabeza; hijab, que cubre la cabeza y el pecho; abaya, que cubre todo el cuerpo y burka o burqa, que cubre el cuerpo y la cabeza (Gruber, 2011; Ramírez, 2011). 
TABLA 2

OBJETIVOS Y CÓDIGOS EN EL ANÁLISIS DE LA INFORMACIÓN

\begin{tabular}{|l|l|}
\hline \multicolumn{1}{|c|}{ objetivos } & \multicolumn{1}{c|}{ Códigos de análisis cerrados } \\
\hline $\begin{array}{l}\text { Análisis de los valores y atributos que se realizan } \\
\text { sobre mujeres migrantes musulmanas }\end{array}$ & $\begin{array}{l}\text { Temáticas que aborda la noticia. } \\
\text { Valoraciones/atributos/estereotipos que se hacen } \\
\text { sobre estas mujeres }\end{array}$ \\
\hline $\begin{array}{l}\text { Análisis de los contextos de producción de dichos } \\
\text { discursos, es decir, desde dónde, por quién y } \\
\text { cuándo la elaboración de noticias }\end{array}$ & $\begin{array}{l}\text { Sección donde se ubica la noticia: extranjero, } \\
\text { actualidad, crónica, política y moda. } \\
\text { Género del autor o autora de la noticia } \\
\text { Procedencia étnica de los y las periodistas } \\
\text { Fecha de la publicación }\end{array}$ \\
\hline
\end{tabular}

Fuente: elaboración propia.

La teoría que seguimos en el análisis de la información sigue los principios de la Teoría Fundamentada (De la Cuesta, 2006; Strauss, Corbin y Zimmerman, 2002) y nos ha resultado útil debido a las posibilidades que ofrece tanto para la creatividad como para la flexibilidad de una investigación de estas características (Creighton, 2013). La interacción constante con los datos y entre nosotras, como investigadoras, nos ha posibilitado llegar a hallazgos emergentes significativos.

\section{RESULTADOS DEL ANÁLISIS}

En primer lugar se aborda el análisis de las imágenes, atributos y representaciones en los tres periódicos analizados. En segundo lugar, se contempla el análisis referente a los contextos de producción: autoría, encuadre y temporalidad.

a) Imágenes, estereotipos y representaciones sobre mujeres migrantes musulmanas en la prensa italiana.

El análisis del contenido de las noticias nos ha mostrado cuatro grandes temáticas en torno a las que se ha organizado el discurso sobre mujeres migrantes musulmanas en la prensa italiana: el velo, el burkini, cuestiones de moda y emancipación laboral. La distribución según el periódico podemos verla en la siguiente tabla (Tabla 3). 
TABLA 3

TEMÁTICAS MÁS FRECUENTES SOBRE MUJERES MUSULMANAS EN LA PRENSA ITALIANA

\begin{tabular}{|l|c|c|c|}
\hline \multicolumn{1}{|c|}{ Temáticas } & La Repubblica & Il Resto del Carlino & Corriere della Sera \\
\hline El velo & $59,2 \%$ & $57,7 \%$ & $13,8 \%$ \\
\hline El burkini & $24,3 \%$ & $30,7 \%$ & $78,9 \%$ \\
\hline La moda & $13,3 \%$ & $7,4 \%$ & $3,7 \%$ \\
\hline Emancipación laboral & $2,2 \%$ & $1,4 \%$ & $1,1 \%$ \\
\hline $\begin{array}{l}\text { Otros: Integración, } \\
\text { asociacionismo, } \\
\text { tradiciones }\end{array}$ & $0,9 \%$ & $2,9 \%$ & $2,4 \%$ \\
\hline Total: & $\begin{array}{c}309 \text { noticias } \\
(100 \%)\end{array}$ & $\begin{array}{c}141 \text { noticias } \\
(100 \%)\end{array}$ & $\begin{array}{c}475 \text { noticias } \\
(100 \%)\end{array}$ \\
\hline
\end{tabular}

Fuente: elaboración propia.

Como podemos ver en la Tabla 3, la distribución de temáticas entre los tres periódicos es la misma a pesar de que el volumen de noticias entre ellos es desigual. Este hecho nos ha resultado llamativo porque a pesar de que cada noticiario tiene una diferente orientación política existe un alto grado de consenso en los tópicos principales sobre los que se discursa a estas mujeres. Las tres principales temáticas: velo, burkini y moda aparentemente pertenecen al mismo ámbito simbólico, el de la imagen corporal, sin embargo, aluden a temáticas diferentes y se asocian a valores distintos por lo que hemos considerado separar su análisis.

En el caso del velo y - especialmente- del burkini se habla mayoritariamente sobre ellos como distintivos de la cultura musulmana, exponentes de la sumisión y de la relación de dominación del hombre sobre la mujer en esta confesión religiosa.

Quel velo alle alunne rischia di essere una divisa (01/07/2003 Corriere della Sera)

Rutelli: no al velo integrale una legge per vietarlo (07/11/2006, La Repubblica)

Si tratta di un simbolo culturale bisogna riflettere prima di vietarlo (10/10/2007 Corriere della Sera)

Burqa a scuola, stop della Carfagna. E' simbolo di sottomissione (13/10/2009, La Repubblica). 
El mensaje que se transmite en las noticias a partir de esta identificación es que no hay posibilidad de integración en la cultura italiana mientras no se renuncie a estas prendas de vestir, en tanto que suponen la visibilización de unos valores (sumisión, machismo, dominación...) contrarios a la cultura europea occidental. Desde esta perspectiva se entiende a la población musulmana de forma homogénea, como un bloque que representa a una civilización y religión atrasada, el Islam, que además supone una amenaza a los valores occidentales y a la sociedad italiana, y cuya forma de manifestación más evidente es la ropa femenina y, junto a ella, las mujeres que la portan.

Qui il burqa è illegale, ma non siamo razzisti (21/07/2007 Il Resto del Carlino).

Il Prefetto di Treviso: "Il burqa è legittimo" Il sindaco: "E se nascondesse un Kamikaze?"(09/10/2007 Il Resto del Carlino).

Fuori legge burqa e niqab in pubblico: primo sì in commissione Camera (03/08/2011 Il Resto del Carlino).

Esta asociación entre prendas de vestir, valores antagónicos y religión musulmana promueve un rechazo hacia estas mujeres que, en algunas ocasiones, llega a convertirse en desconfianza y temor cuando se asocia a violencia y terrorismo. En el caso del burqa se menciona la posibilidad de su uso como lugar donde esconder el explosivo para perpetrar atentados $\mathrm{u}$ otros objetos peligrosos, promoviendo la desconfianza hacia las mujeres veladas. En otras noticias se habla de la imposibilidad del uso del burka o del burkini en espacios públicos como playas o piscinas, donde no se entiende la necesidad de nadar vestidas. Se justifica su prohibición en base a cuestiones sanitarias y de higiene, deslizando la idea de suciedad o poca limpieza de las mujeres vestidas, aunque este argumento nunca se menciona directamente.

Nuotare col chador in piscina si può (03/08/2004 La Repubblica) In piscina niente bagno col chador (08/09/2004 La Repubblica)

$\mathrm{Va}$ in piscina con il burkini le mamme protestano a Verona (19/08/2009 La Repubblica)

A Varallo burkini vietati in piscina e nei fumi (23/08/2009 Il Resto del Carlino)

"Il mio burkini? A norma: è di nylon. Non è un'imposizione, lo faccio per me (26/08/2009 Il Resto del Carlino)

Fuori legge burqa e niqab in pubblico: primo sì in commissione Camera (03/08/2011 Il Resto del Carlino) 
Es especialmente en el períódico La Repúbblica donde el discurso sobre el rechazo y el miedo a lo velado resulta más homogéneo. La mayoría de los artículos sobre el hiyab y el burqa pivotan sobre la regulación que debería tener la vestimenta de estas mujeres en los espacios públicos, ya que se entiende que supone no sólo una falta de libertad para ellas sino una continua visibilización de la obediencia y supeditación a sus maridos. Eliminar el uso de estas prendas de vestir supondría, desde este posicionamiento, una forma de equipararlas al estatus de las mujeres occidentales italianas, salvándolas de la obligación impuesta por una cultura patriarcal y machista.

Il Viminale contro il burqa è un'offesa alle donne (20/10/2006 Corriere della Sera)

Intesa bipartisan sul burqa il Consiglio provinciale: "No al velo integrale" (15/02/2010 Il Resto del Carlino)

Lo, picchiata e umiliata per il velo (31/03/2012, La Repubblica)

Se una modella con il velo divide il mondo (30/09/2015 La Repubblica)

A pesar de la problematización general que se realiza tanto de la vestimenta de estas mujeres como sobre ellas mismas por portarlas, de forma minoritaria observamos posicionamientos críticos con esta situación. Se trata de artículos fundamentalmente publicados por Il Corriere de la Sera. En ellos se reflexiona sobre la complejidad del uso del velo islámico así como las implicaciones morales que supone su prohibición, ya que limita la libertad de expresión de las mujeres. También se hace una crítica explícita a los posicionamientos de la Lega, un partido de derecha que se opone al uso del burqa en las mujeres musulmanas y que propone penalizarlo con sanciones incluso de cárcel.

Milano, la Lega apre il caso burqa "impediamo alle donne l'uso del velo" (21/09/2004 Corriere della Sera)

Lo stile musulmano conquista la moda (28/10/2018 Corriere della Sera)

La sfilata di moda delle musulmane "oltre gli stereotipi" (12/05/2018 Corriere della Sera)

Este tipo de artículos son minoritarios y a pesar de que fomentan una actitud crítica hacia planteamientos reaccionarios no hemos encontrado propuestas abordadas con profundidad sobre posibili- 
dades de encuentro o aceptación de las características particulares de esta forma de vestir, por lo que la única vía para la integración de estas mujeres que se sugiere, tanto en este periódico como en los demás, es la uniformidad con la moda occidental de las mujeres italianas.

Todas estas aproximaciones tienen en común el haber establecido un marco de sentido en el que lo prioritario es la ropa, la imagen corporal de estas mujeres como principal atributo a través del cual son representadas, definidas y pensadas. En la mayor parte de los casos, ellas y su vestimenta son entendidas como símbolo de amenaza y problema, frontera física y visual de un grupo frente a otro. En otros casos, más minoritarios, la vestimenta es asociada al consumo y la belleza. Son los artículos que vamos a mencionar a continuación en los que se habla de estas mujeres y su relación con la moda.

La moda es la tercera temática en importancia del discurso sobre mujeres migrantes musulmanas. La prensa italiana habla de ellas como prioridad para estilistas, mostrando especial interés por llegar a su segmento de consumo. Al utilizar prendas de vestir diferentes a las utilizadas por las mujeres occidentales se habla de hijab, burqa, burkini en clave moderna y se menciona cómo Alberta Ferretti o Dolce e Gabbana presentan sus prendas a mujeres con alto nivel adquisitivo y social. En estos casos, a diferencia de los anteriores, el contexto del discurso se realiza en términos de consumo, ocio y clase social. Se habla de mujeres que llevan burqas preciosos pero que debajo visten de forma occidental, con ropa muy cara diseñada por famosos estilistas italianos.

Il mistero della modella che difende le donne (08/03/2008 La Repubblica)

Dolce e Gabbana presentano la prima collezione per donne musulmane (07/01/2016 Il Resto del Carlino)

Alberta Ferretti, in passerella c'è anche la modella con l'hijab (22/02/2017 Il Resto del Carlino)

Halima il velo in passerella: gli integralisti mi criticano (23/02/2017 Corriere della Sera)

En estos casos la moda si se identifica con belleza y estilo, se habla de las dificultades que tienen las mujeres musulmanas en ser aceptadas por su manera de vestir e incluso, en algunas noticias, se menciona cómo el hecho de llevar estas prendas supone una forma de evidenciar su particularidad e identidad personal. 
La penúltima temática en volumen de noticias del total de artículos analizados ha sido la emancipación laboral. Es la cuarta en importancia pero realmente solo hemos encontrado catorce artículos entre los tres periódicos. En ellos se habla de mujeres que han emprendido negocios propios pero se aborda como si fuera un acontecimiento extraordinario. Por ejemplo, el caso de una chica musulmana que abrió una tienda de pañuelos en Bologna (Nuova imprenditoria musulmana, ragazza apre negozio di veli, 16/04/2018, Il Resto del Carlino). De ella se resalta su coraje y valor para iniciar un proyecto en solitario y se reconoce de forma muy significativa su autonomía por hacerlo en un lugar ajeno y extraño pero se aborda como si fuera una anomalía dentro de su comunidad. En otros artículos se menciona también la creación de plataformas $\mathrm{y}$ foros en los que las musulmanas reivindican su derecho a ser reconocidas como ciudadanas y trabajadoras productivas, pero estos hechos no dejan de contemplarse como algo anecdótico, por lo que frecuentemente reciben un tratamiento superficial en el que no se ahonda o investiga la verdadera situación de estas mujeres.

Shirin Neshat "Il mio film parla di donne capaci di cambiare il mondo" (28/10/2018 La Repubblica). Sera)

Il Corano, l'Islam, le donne, il lavoro (18/10/2002 Corriere della

Il forum delle musulmane: non siamo fantasmi (27/01/2007 Corriere della Sera)

Por último, aunque minoritarios, hemos encontrado artículos con temáticas que muestran los procesos de emancipación y discriminación que sufren estas mujeres musulmanas. Son artículos que abordan las dificultades que encuentran para integrarse dentro de los distintos ámbitos de la sociedad como el educativo, social, cultural o político.

Milano studentessa va in classe col velo (27/11/2011 Il Resto del Carlino)

Con o senza velo lasciamo decidere alle donne musulmane (03/03/2014 Il Resto del Carlino)

Il coraggio delle islamiche. "Basta violenze e soprusi" (02/04/2017 Il Resto del Carlino).

La comica musulmana: "scherzo su Bin Laden" (21/10/2001 Corriere della Sera)

Sotto quei veli la battaglia delle donne musulmane (17/08/2008 Corriere della Sera) 
En ellos se da voz a las propias mujeres migrantes para que cuenten su historia o se habla sobre ellas pero desde un posicionamiento crítico, evidenciando su posición de desigualdad. Se abordan temas como el acceso y/o la vulneración de derechos, la precariedad o su emancipación y se visibiliza su diferencia como valor. Son artículos escritos en su mayoría por mujeres, como veremos en el apartado posterior.

Lo felice e onorata di indossare il niqab (11/02/2010, La Repubblica)

Integrazione come valore (03/08/2011 La Repubblica)

Sara, crocerossina col velo: "Io, l'Islam e il volontariato" (24/09/2014 La Repubblica)

Shirin Neshat "Il mio film parla di donne capaci di cambiare il mondo" (28/10/2018 La Repubblica)

Cinzia Sciuto"Fede e identità non vanno insieme. Servono diritti uguali per tutti" (24/11/2018, La Repubblica)

En general, en estas noticias se utiliza un tono más solidario, dando importancia a contar historias concretas en primera persona sobre experiencias de superación y constancia. Algunos de estos artículos se convierten en relatos de salvación, éxito meritocrático y ascenso social, como el caso de Halima Aden procedente de un campo de refugiados que ha llegado a ser Miss Minnesota (Halima Aden "Orgogliosa di essere diversa", 10/10/2017, La Repubblica). Pero aún siendo conscientes de los sesgos patriarcales o etnocéntricos que subyacen detrás de estas historias, la escasez de las mismas en relación a otros colectivos muestra la invisibilidad individual que tienen estas mujeres en las noticias de la prensa y, junto a ello, sus experiencias, opiniones y proyectos de vida.

b) Autoría, encuadre y temporalidad de las noticias publicadas sobre mujeres migrantes musulmanas en la prensa italiana.

En relación a la autoría de las noticias hemos analizado dos variables: la procedencia étnica y el género. Con respecto a la primera, del total de documentos analizados solo un 5\% de las noticias han sido escritas por periodistas de procedencia extranjera ${ }^{4}$. Un dato común a los tres periódicos que revela el escaso protagonismo de

4 Para averiguar la nacionalidad de los y las periodistas de procedencia extranjera, hemos hecho una búsqueda en redes sociales de los/las que poseen apellidos no italianos. Siendo conscientes del sesgo de este criterio, creemos que tiene una alta correspondencia con los datos reales. 
voces no nacionales para hablar sobre extranjería, y que coincide con los señalado en otras investigaciones sobre inmigración en el contexto europeo (Van Dijk, 2008).

La procedencia de estos periodistas se circunscribe al continente europeo y norte de África (alemana, argelina, inglesa, marroquí y francesa) y, a pesar de que solo hay 30 noticias que hemos estimado de procedencia extranjera, su relato es diferente al resto, mostrando un discurso más positivo, menos homogéneo y estereotipado sobre la inmigración, no así sobre el género. Esto se observa, especialmente, en el caso de artículos escritos por periodistas argelinos o marroquíes, que muestran la pluralidad de posicionamientos dentro del mundo musulmán sobre un tema: Le donne musulmane: no alla censura su Van Gogh (Allam Magdi Cristiano, Corriere della Sera 19/04/2005) o Noi, ragazze musulmane anti-jihad (Tahar Ben Jelloun, La Repubblica 28/03/2017) no así la heterogeneidad de posicionamientos dentro de las mujeres.

En relación al género, solo entre un 16\% y 35\% del total de las noticias analizadas han sido escritas por mujeres, como puede verse en el gráfico 1. Es decir, existe una infrarrepresentación de mujeres periodistas en la publicación de noticias sobre población femenina musulmana con respecto a los hombres.

\section{GRÁFICO 1}

GÉNERO EN LA AUTORÍA DE LAS NOTICIAS SOBRE MUJERES MUSULMANAS EN LA PRENSA ITALIANA

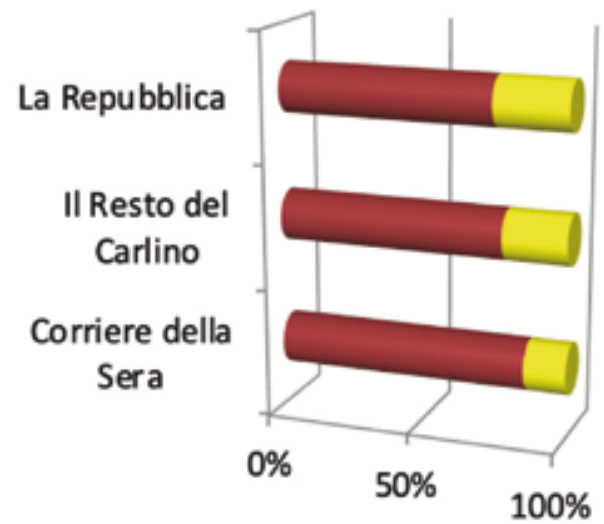

\section{- Artículos totales}

Escritos por mujeres periodistas

Fuente: elaboración propia. 
En el caso del periódico La Repubblica, solo un 34\% del total de las noticias (107 sobre 309) han sido escritas por mujeres. En el caso del Il Resto del Carlino este porcentaje desciende a un $28 \%$ (40 de 141) y en el Corriere della Sera aún baja más, hasta un 16\% (79 de 475) sobre el total. Es decir, la voz del hombre es la que se utiliza de forma mayoritaria para hablar sobre mujeres extranjeras. Asimismo, no observamos una correlación entre la orientación política del periódico (eje izquierda/derecha) y un aumento o disminución en la autoría de noticias según el género del autor o autora. Es cierto que La Repubblica, un periódico de centro-socialdemocracia, tiene el mayor porcentaje de periodistas femeninas que escriben sobre mujeres (un 34\%), pero el Corriere della Sera, que es un periódico de izquierdas, presenta el porcentaje inferior, con solo un $16 \%$.

Sin embargo, sí que hemos observado diferencias significativas en la forma de abordar las noticias y temáticas según la autoría en función del género. Concretamente, los artículos escritos por mujeres suelen dar voz a las mujeres musulmanas en mayor medida que los hombres, muestran una mayor solidaridad con esta población y abordan cuestiones como la emancipación laboral, autonomía, superación, desigualdad o discriminación jurídica: Integrazione come valore (03/08/2011, La Repubblica), Il coraggio delle islamiche. "Basta violenze e soprusi" (02/04/2017 Il Resto del Carlino), Halima Aden "Orgogliosa di essere diversa" (10/10/2017, La Repubblica). Estas temáticas y perspectivas también las hemos encontrado en noticias escritas por voces masculinas, de ahí que no podemos hablar de discursos diferenciados según género, pero las formas de abordaje mas empáticas, solidarias y cuestionadoras del status quo, así como la noticias que han incluido temáticas no discriminatorias y menos estereotipadoras han sido escritas por mujeres.

En relación a la ubicación/encuadre de las noticias, la mayor parte de la información analizada pertenece a las secciones de Actualidad, Crónica y Política (ver Tabla 4). Entre estas tres secciones acumulan el $75 \%$ del total de noticias analizadas aunque su distribución es tan heterogénea entre los tres periódicos que se hace necesario un análisis particular de cada caso. 
TABLA 4

UBICACIÓN DE LAS NOTICIAS ANALIZADAS SOBRE MUJERES MUSULMANAS EN LA PRENSA ITALIANA SEGÚN PERIÓDICO Y SECCIÓN

\begin{tabular}{|l|c|c|c|}
\hline & LA REPUBBLICA & IL RESTO DEL CARLINO & CORRIERE DELLA SERA \\
\hline Extranjero & 51 & 42 & 26 \\
\hline Actualidad & 78 & 60 & 9 \\
\hline Crónica & 49 & 11 & 188 \\
\hline Política & 63 & 19 & 218 \\
\hline Moda & 68 & 9 & 34 \\
\hline Total & $309(34 \%)$ & $141(15 \%)$ & $475(51 \%)$ \\
\hline
\end{tabular}

Fuente: elaboración propia.

Como observamos en la tabla superior (Tabla 4), la distribución de noticias entre los tres periódicos es muy desigual, siendo el Corriere della Sera el que más noticias ha publicado sobre mujeres migrantes musulmanas, con un $51 \%$, seguido de La Repubblica, con un 34\% y, en tercer lugar, Il Resto del Carlino, con solo un 15\% de las noticias analizadas. La distribución de los artículos entre diferentes secciones es bastante heterogénea, llegando a ser opuesta en algunos casos. Para no infravalorar los resultados de los periódicos con menor cantidad de información se hace necesaria una valoración individual.

En el periódico La Repubblica las secciones de actualidad y moda son las más representativas. En Il Resto del Carlino también la sección de actualidad es la que acumula más artículos pero seguida de la sección de extranjeros. Estas dos secciones, actualidad y moda, se caracterizan por la publicación de noticias desde una óptica sensacionalista, mayoritariamente orientada a comentar acontecimientos significativos de la sociedad italiana. Frente a ellos, el Corriere de la Sera presenta una distribución opuesta, ya que las dos secciones más importantes son las de Crónica y Política, que utilizan mayoritariamente una óptica gubernamental y legislativa para hablar sobre mujeres migrantes musulmanas. Las categorías que tienen menor volumen de información también difieren según 
el periódico. En La Repúbblica la sección de crónica es la que menos noticias presenta, en Il Resto del Carlino la de moda y en el Corriere de la Sera la de actualidad. Las ubicaciones de las noticias en los diferentes periódicos y la proporción de las mismas dentro de cada sección reflejan apuestas por trabajar esta temática desde un marco de sentido diferente, en algunos casos más vinculado a una dimensión institucional (el Corriere de la Sera) y en otros a noticias de impacto social (La Repubblica).

En último lugar, dentro de este primer apartado, observamos la dimensión temporal en la publicación de noticias sobre mujeres musulmanas a lo largo de estas dos décadas. Como apreciamos en el Gráfico 2, existen momentos marcados de incremento y descenso en la publicación de artículos sobre esta población.

GRÁFICO 2

DISTRIBUCIÓN TEMPORAL DE LA PUBLICACIÓN DE NOTICIAS SOBRE MUJERES MIGRANTES MUSULMANAS EN LA PRENSA ITALIANA SEGÚN PERIÓDICO (2001-2018)

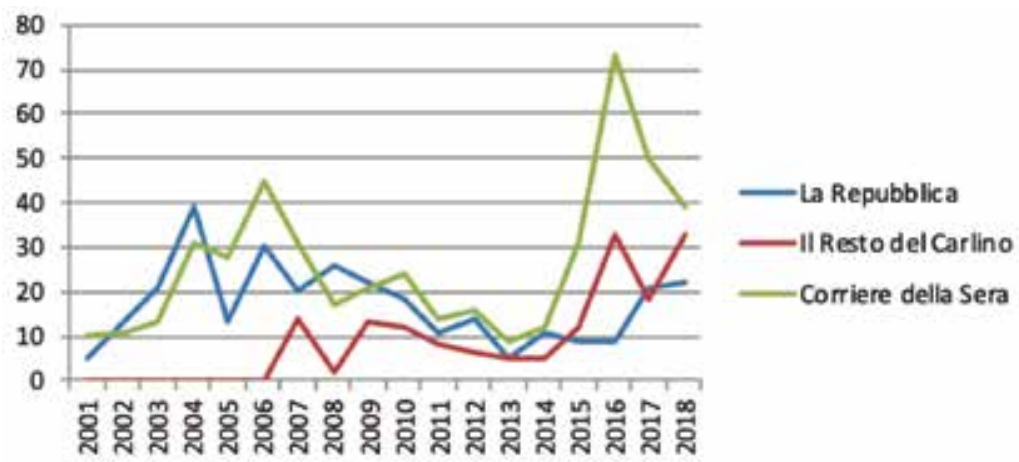

Fuente: elaboración propia.

Tal como vemos en el gráfico superior (Gráfico 2) existen ciertas similitudes entre los tres periódicos en la existencia de picos y valles en periodos temporales concretos y si bien la cantidad de artículos es diferente entre los noticiarios, podemos observar cierta correspondencia entre los momentos de incremento y decrecimiento de publicación de noticias y cambios de leyes sobre migración. Así 
vemos como a partir el año 2001 se inicia un periodo progresivo en la publicación de noticias que termina en el bienio 2004-05 y que vuelve a subir en el año 2005-2006 bajando en el 2007-2008, un periodo en el que se publica y termina la ley Bossi-Fini. Junto a ello observamos un descenso generalizado en la información durante varios años hasta el año 2013-14 en el que comienza a subir la producción de noticias hasta el pico del año 2016 (excepto en La Repubblica), en el que se publica el Decreto Minniti. Los valles los observamos desde el año 2008 hasta el 2014, periodo en que no se publicaron nuevas leyes y se mantuvo el Pacchetto Sicurezza del Gobierno Berlusconi. Una ley muy restrictiva que introdujo el delito sobre inmigración irregular.

Esta correspondencia muestra una relativa vinculación entre la publicación de normativa sobre extranjería y aumento del discurso sobre inmigración. Sin embargo, no observamos esta misma relación con los procesos electorales (2001, 2006, 2008, 2013, 2018). En esos años no identificamos picos significativos en la producción de discurso de forma regular, por lo que inducimos que las elecciones generales en Italia han influido en menor medida que las modificaciones legislativas en la producción de discurso mediático sobre mujeres musulmanas. Una correlación diferente a la de otros contextos como el español, donde el discurso sobre inmigración, especialmente el parlamentario, si ha oscilado a la par que los procesos electorales (Márquez-Lepe, 2015).

\section{DISCUSIÓN Y CONCLUSIONES}

A la luz de los artículos analizados podemos señalar que la manera que tiene la prensa italiana de representar a las mujeres musulmanas migrantes es, fundamentalmente, como problema. Esto se manifiesta de diferentes formas.

En primer lugar, existe una ausencia de contextualización de términos arabo-islámicos en los tres periódicos analizados como, por ejemplo: abaya, burka, burkini, niqab, hijab o chador. Éstos conceptos se utilizan de forma frecuente sin mencionar en ningún momento que significan, que uso han tenido y cuál es su función actual, por lo que consideramos que su empleo más que ayudar a entender el fenómeno islámico ahonda en su estereotipación, 
respondiendo así al papel que en las actuales sociedades occidentales se le ha asignado al islam y a la población musulmana (Dragoevic y Bodas, 1994).

En segundo lugar, al igual que ha venido ocurriendo cuando se habla sobre mujeres en la prensa (Proyecto GMMMP, 2015), el discurso sobre migrantes musulmanas ha estado elaborado fundamentalmente por periodistas masculinos, blancos y occidentales. Del total de noticias analizadas solo treinta, es decir, un $5 \%$, han estado escritas por periodistas de nacionalidad extranjera, como sucede con las noticias sobre inmigración en general (Van Dijk, 2008), y solo el $24 \%$ (de media) ha sido escrita por mujeres. Ambos hechos han modulado tanto la forma de abordar las noticias como la elección de las temáticas y, si bien no es una situación novedosa, muestran que los medios no hacen sino reflejar los prejuicios y actitudes enraizados en el sistema de valores dominante (Checa, 2008; Nash, 2007; Rovetto, 2010). Frente a ello, existen iniciativas como los protocolos de actuación periodística y publicitaria sobre igualdad de oportunidades entre mujeres y hombres, tratamiento informativo de la violencia de género o inmigración (López, 2007, Rodrigo, 2006) que abogan por desarrollar un discurso de género, plural e intercultural, y que recomendamos seguir como guías para superar el relato hegemónico construido sobre estas y otras mujeres.

En tercer lugar, el discurso mayoritario sobre migrantes musulmanas se ha elaborado fundamentalmente desde un planteamiento político e institucional. Este hecho junto a la prevalencia de la voz masculina para hablar sobre mujeres pensamos que no es casual sino que responde a la reproducción del ámbito y la lógica en la que el hombre se ha socializado y ha desarrollo su actividad profesional, la esfera pública (Lamas, 2003). En este discurso las mujeres han ocupado una posición de sumisión y subalternidad continua (Chiappelli, 2009; Gaudino, 2019) y consideramos que han sido representadas desde una mirada patriarcal, etnocéntrica y heteronormativa, como señalaban Sobrados-León y Sánchez (2008), Solano (2012) o Corte (2002) para otras investigaciones.

Identificamos en estos discursos una mirada patriarcal pues en la mayor parte de las noticias analizadas son los autores (mayoritariamente hombres) los que interpretan cuales son las necesidades que tienen estas mujeres y, como consecuencia de ello, las soluciones que necesitan. Las imágenes que proyectan habitualmente sobre ellas las presentan como víctimas, pasivas y sumisas a merced de la 
voluntad de sus maridos o de una religión opresiva de la que deben ser salvadas. Personas incapaces de tomar las riendas de su vida, por lo que las ocasiones en que lo consiguen son interpretadas como excepción y novedad.

Señalamos una mirada etnocéntrica porque se las ha significado como meras reproductoras de una cultura a través del uso del velo y el hiyab. Elementos que han sido identificados como ofensivos, cuando no directamente amenazantes para la convivencia en la sociedad italiana actual, por lo que sus portadoras también han pasado a serlo. No es casual que cerca del $80 \%$ de las noticias analizadas traten sobre el velo y el burkini como símbolo no solo de la mujer musulmana sino de la musulmaneidad. Su visibilización en el espacio público se ha utilizado como justificación de choque cultural, asociando su uso a la idea de confrontación, conflicto y, en ocasiones, a violencia y terrorismo, una constante en el discurso de los medios sobre la población musulmana, tal como han señalado Louassini (2002) o Solano (2012). El velo y el burkini son utilizados como símbolos de una cultura subalterna, tradicional y sin capacidad de transformación histórica (Salas, 2012). Asimismo, su reticencia a dejar de llevar esta vestimenta responsabiliza a estas mujeres de su poca capacidad de integración, de manera que responsabilidad y culpa se entrelazan sin posibilidad de distinción. Estos resultados validan la hipótesis de que la mayoría de las noticias proporcionadas por los periódicos, como afirma Simelio i Solá (2006), en lugar de orientarnos en el mundo en que vivimos y proporcionarnos datos y criterios para valorar los acontecimientos, construyen una información más opaca, más alejada de la realidad y más deshumanizada.

De forma paralela a lo anterior, encontramos una mirada heteronormativa que reproduce los roles tradicionales asignados a cada sexo. Roles dicotómicos y jerarquizados en el que se cosifica de la mujer migrante musulmana a través de su imagen corporal, que se define como el atributo principal y definitorio de su identidad. En los tres periódicos analizados es muy revelador que del total de las 925 noticias analizadas, el 54\% tratan el tema de la cuestión del velo, el $28 \%$ el burkini y el $12 \%$ la moda. La asociación de la mujer con su aspecto físico y corporal es una de las constantes en la representación que se ha hecho tradicionalmente del sexo femenino. De esta forma no se rompe con la tradición de entender a la mujer a través de su imagen pública sino que a ello se le añade su representación cultural. 
Desde esta mirada también se reproducen los tópicos habituales que, por un lado, ignoran su capacidad de agencia y su independencia cultural e ideológica (Martín, 2006). Es decir, no se las contextualiza, se habla de ellas como si fueran un todo homogéneo extraño, sin hacer referencia a las causas y motivos de su proceso migratorio ni al contexto italiano donde viven. Sólo en algunos artículos se hace referencia a la resistencia y capacidad crítica de estas mujeres pero incluso esos casos son narrados con muy poca concreción. Por otro lado, al ser depositarias y a la vez reproductoras de una cultura antagónica a la occidental, son entendidas como sospechosas de actos potencialmente delictivos así como portadoras de una amenaza global que hay que controlar y neutralizar. Legitiman la distinción entre inmigradas buenas y malas, las que creen en los valores occidentales y las que no, como señalaba Corte (2002). Estamos de acuerdo, como señalaba Nash (2007) que en éstas mujeres convergen una identidad mediática en la que la interacción de factores de género y diferencia cultural les genera una mayor marginalización, cosificación e invisibilización del debate público. Como señalaba Craighton (2013), su discurso es un discurso de otredad pero también de ausencia.

Todos estos resultados no hacen sino evidenciar la necesidad de analizar las migraciones y las migraciones femeninas en clave interseccional, como manifiestan Creighton (2013) o Sobrados-León y Sánchez (2008), una mirada muy necesaria tanto para ampliar el conocimiento de las migraciones como su impacto diferencial en mujeres y hombres.

\section{BIBLIOGRAFÍA}

Alcoba, S. (2009). Lengua, comunicación y libros de estilo. Madrid: Digital Edition.

Bañón, A. M. (2002). Discurso e inmigración: propuestas para el análisis de un debate social. Murcia: Universidad de Murcia.

Benach, N. y Tello, R. (2005). Mujeres en el mundo. Historia, retos y movimientos de Mary Nash. Lectora: revista de dones i textualitat, 11, 283-289. Recuperado de:https://ddd.uab.cat/pub/lectora/20139470n11/20139470n 11p283.pdf

Bernárdez Rodal, A. (2007). Mujeres inmigrantes en España. Representaciones en la información y percepción social. Informe técnico. Madrid: 
Fragua. Recuperado de https://eprints.ucm.es/11482/1/libro_de_ASUNCIO_BERNARDEZ.pdf

Bruno, M. (2008). L'Islam immaginato: Rappresentazioni e stereotipi nei media italiani. Roma: Guerini scientifica.

Buisef, D. (1994). Medios de comunicación y visiones del Magreb. La percepción Norte/Sur en la prensa española. Voces y Culturas, 6, 11-21.

Cáceres, M. D. (1987). Estrategias representativas del acontecer y su estructura en el periodismo radiofónico. Telos: Cuadernos de Comunicación, Tecnología y Sociedad, 11, 77-85.

Carmignani Caridi, S. (2000). Libertà di abbigliamento e velo islamico. En Ferrari, A. (a cura di), Musulmani in Italia. Bologna: Il Mulino, 223-234

Chiappelli, T. (2009). Qui in Italia tutto è diverso...: religione e religiosità nelle storie di vita di donne musulmene immigrate in Italia. Religione e Societá, XXIV (64), 1000-1007. Recuperado de https://www.academia. edu/24926976/Qui_in_Italia_e_tutto_diverso_Religione_e_religiosita_nelle_storie_di_vita_di_donne_musulmante_immigrate_in_Italia

Chiodelli, F. (2015). La spazialità islamica nelle città italiane: rilevanza, caratteristiche ed evoluzione. Archivio di Studi Urbani e Regionali, 2. doi: 10.3280/ASUR2015-113004

Corte, M. (2002). Noi e gli altri. L'immagine dell'immigrazione e degli immigrati sui mass media italiani. Peacelink. Telematica per la pace. Recuperado de: https://www.peacelink.it/migranti/a/121.html

Creighton, H. (2013). (De) construir la otredad: las mujeres inmigrantes en la prensa escrita española. Revista de Paz y Conflictos, 6, 78-106.

Checa Olmos, F. (2008) Las migraciones a debate y el debate de las migraciones. En Checa Olmos, F. (coord.) La Inmigración Sale a la Calle: comunicación y discursos políticos sobre el fenómeno migratorio (pp. 7-16). Barcelona: Icaria

De la Cuesta, C. (2006) La teoría fundamentada como herramienta de análisis. Revista de enfermería y humanidades, 20, (2), 136-140. doi: //doi. org/10.14198/cuid.2006.20.19

Dedej, A. (2004). La rappresentazione sociale della donna musulmana in alcuni quotidiani della stampa italiana. Tesis doctoral. Recuperada de https:// www.tesionline.it/tesi/la-donna-in-al-andalus-aspetti-storici-e-contemporanei/14328

Dragoevic, A., \& Bodas, J. (1994). El mundo árabe y su imagen en los medios. Madrid: Comunica

Fairclough, N. (2003). El ACD como método para la investigación en ciencias sociales. En R. Wodak y M. Meyer (eds.) Métodos de análisis crítico del discurso (pp. 179-201). Barcelona: Gedisa.

Gallotti, C. y Maneri, M. (1998). Elementi di analisi del discorso dei media. Lo'straniero'nella stampa quotidiana. En Tabet P., Di Bella S. A cura di. Io non sono razzista ma... Strumenti per disimparare il razzismo (pp. 6388). Torino: Anicia. 
Gaudino, U. (2019). La stampa italiana e il burkini: una rappresentazione orientalistica dell'Islam. Iriad Review. Studi sulla pace e sui conflitti, 43-55.

Global Media Monitoring Project (2015). Who Makes the News?. Informe técnico. Recuperado de http://whomakesthenews.org/gmmp/gmmp-reports/gmmp-2015-reports

Gómez, L. (2010). Un espacio para la investigación documental. Revista Vanguardia Psicológica Clínica Teórica y Práctica, 1(2), 226-233.

Gruber, L. (2011). Figlie dell'Islam. La rivoluzione pacifista delle donne musulmane Roma: Rizzoli.

Istituto Nazionale di Statística, INS. (2018). Vita e percorsi di integrazione degli immigrati in Italia.

Lamas, M. (2003). La antropología feminista y la categoría 'género'. En M. Lamas, El género. La construcción cultural de la diferencia sexual (pp.97125). México DF: PUEG.

Louassini, Z. (2002). La imagen del árabe en los medios de comunicación occidentales. Miscelánea de Estudios Árabes y Hebraicos. Sección ÁrabeIslam, 51, 67-90.

López Díez, P. (2007). Protocolo de actuación periodística y publicitaria sobre igualdad de oportunidades entre mujeres y hombres y tratamiento informativo de la violencia de género. Unidad de Igualdad de Género. Gobierno de Cantabria: Vicepresidencia Dirección General de la Mujer. Informe. Recuperado de https://www.redalyc.org/pdf/2050/205027536004.pdf

Maneri, M. (2009). I media e la guerra alle migrazioni. En S. Palidda (a cura di), Razzismo democratico. La persecuzione degli stranieri in Europa (pp. 66-86). Milano: Agenzia X.

Marchetti, S. (2004). Le donne delle donne. DonnaWomanFemme, 1-2, 68-98.

Márquez-Lepe, E. (2015). Representaciones, identidades y nacionalismos en el discurso político español a propósito de la inmigración. En C. Sieber et al. (comps). Nación y migración. España y Portugal frente a las migraciones contemporáneas (pp. 137-153). Madrid: Biblioteca Nueva.

Martín Casares, A. (2006). Antropología del género: culturas, mitos y estereotipos sexuales. Madrid: Cátedra.

Masanet Ripoll, E., y Ripoll Arcacia, C. (2008). La representación de la mujer inmigrante en la prensa nacional. Papers: revista de sociología, 89, 169-185.

McCombs, M., y Evatt, D. (1995). Los temas y los aspectos: explorando una nueva dimensión de la agenda setting. Comunicación y Sociedad, 8(1) 7-32.

Monaci, L. S. (2016). Genere e pregiudizio: l'atteggiamento delle donne italiane verso le donne immigrate. Scienze e Ricerche, 37(15), 8-18.

Nash, M. (2007). Repensar las representaciones mediáticas de las mujeres inmigrantes. Quaderns de la Mediterrània, 7, 59-62.

Novoa, M. (2012). Diferencia entre la perspectiva de género y la ideología de género. Díkaion: revista de actualidad jurídica, 21(2), 337-356.

Orrú, P. (2015). Razzismo quotidiano: la rappresentazione dello straniero nella stampa italiana (2000-2010). Tesis Doctoral. Cagliari: Università 
degli studi di Cagliari. Recuperado de https://iris.unica.it/retrieve/handle/11584/266401/345837/PhD_Thesis_Orru_Paolo.pdf

Pacini, A. (2000). I musulmani in Italia. Dinamiche organizzative e processi di interazione con la societta e le istituzioni italiane. En Ferrari, S. (Ed.) Musulmani in Italia. La condizione giuridica delle comunit †a islamiche (pp. 21-39).Bologna: Il Mulino.

Peñamarín, C. (1997). El análisis de textos en una nueva clave. Discursos e Imágenes Sobre la Inmigración en El País. CIC: Cuadernos de información y comunicación, 3, 145-166.

Pérez, C. (2003). Las inmigrantes en la prensa: víctimas sin proyecto migratorio. Mugak, 24. Recuperado de http://www.mugak.eu/revista-mugak/ no-24/las-inmigrantes-en-la-prensa-victimas-sin-proyecto-migratorio

Ramírez, A. (2011). La trampa del velo. El debate sobre el uso del pañuelo musulmán. Madrid: Catarata.

Rizo, M. (2001). Miedo y compasión: dos estrategias de movilización afectiva en el discurso informativo sobre el inmigrante. Revista Comunica, 2. Recuperado de https://ddd.uab.cat/pub/papers/02102862n89/0210286 2n89p169.pdf

Rodrigo Alsina, M. (2006). El periodismo ante el reto de la inmigración. En M. Lario Bastida (coord). Medios de comunicación e inmigración (pp. 37-58). Murcia: Caja de Ahorros del Mediterráneo-Obra social.

Rovetto, F. L. (2010). La representación del trabajo de las mujeres en los medios de comunicación. El caso de las mujeres inmigrantes. Nómadas, 28 (4). Recuperado de https://www.redalyc.org/pdf/181/18118913006. pdf

Salas, A. (2012). Aportaciones del feminismo islámico como feminismo poscolonial para la emancipación de las mujeres musulmanas. Trabajo de fin de Máster, Máster universitario en estudios feministas. Universidad Complutense de Madrid. Recuperado de https://eprints.ucm.es/16838/1/ TFM_ANA_SALAS_SEPT._2012.pdf

Simelio i Solà, N. (2006). Prensa de información general durante la transición política española (1974-1984) pervivencias y cambios en la representación de las relaciones sociales. Tesis Doctoral. Universitat Autónoma de Barcelona. Recuperado de https://dd.uab.cat/pub/tesis/2006/tdx-0327107160534/nss1de1.pdf

Siruana, J. C., y Gracia, J. (2004). Análisis ético. La inmigración en la prensa valenciana. Valencia: Centro de Estudios para la Integración Social y Formación de Inmigrantes. Recuperado de https:/ddd.uab.cat/pub/pape rs/02102862n89/02102862n89p169.pdf

Sobrados-León, M., y Sánchez, H. (2008). Ellas víctimas, ellos delincuentes. La imagen de los inmigrantes en los medios de comunicación. Comunicación, identidad y género, 1, 380-393.

Solano, G. (2012). L'immigrazione nelle notizie dell'Ansa. Informe de investigación. Recuperado de https://www.academia.edu/3160111/L_immigrazione_nelle_notizie_dell_Ansa 
Strauss, A. L., Corbin, J., y Zimmerman, E. (2002). Bases de la investigación cualitativa: técnicas y procedimientos para desarrollar la teoría fundamentada. Medellín: Editorial Universidad de Antioquia.

Valencia, V. E. (2012). Revisión documental en el proceso de investigación. Informe técnico. Universidad Tecnológica de Pereira. Recuperado de https://univirtual.utp.edu.co/pandora/recursos/1000/1771/1771.pdf

Van Dijk, T. (2000). El discurso como interacción social. Barcelona: Gedisa

Van Dijk, T. (2008). Racismo, Prensa e Islam. Revista de Derechos Humanos. Derechos humanos y diversidad cultural y religiosa. Musulmanes en Europa, 17-20.

Zatti, G. (2007). L'Islam d'Italia: racconto di un percorso. Islam of Italy: tale of a journey). Islamochristiana, 33, 163-197. 